\title{
The Procambarus clarkii (red swamp crayfish) in Merja Zerga wetland in Morocco: Dynamic and impacts on aquatic vegetation
}

\author{
Sara Saguem, ${ }^{1}$ Abdelouahab Sahli, ${ }^{2}$ EL Habib Jdi, ${ }^{3}$ Majida El Alami El Moutaouakil,, 4 \\ ${ }^{1}$ Research Team Ecology, Systematics, Conservation of Biodiversity, Department of Biology, Faculty of Science, Abdelmalek \\ Essaadi University, Tetouan; ${ }^{2}$ Applied Botany Laboratory, Bio-Agrodiversity Team, Department of Biology, Faculty of \\ Science, Abdelmalek Essaadi University, Tetouan; ${ }^{3}$ Regional direction of water and forests and the fight against desertification \\ northwestern Kenitra; ${ }^{4}$ Department of Biology, Faculty of Science, Abdelmalek Essaadi University, Tetouan, Morocco
}

\begin{abstract}
Procambarus clarkii, one of the most invasive aquatic species in the world, is present in the Mediterranean estuarine regions. The invasion of this species in these wetlands has a multitude of impacts, including the impact on flora. This study examines the floristic diversity and abundance of Procambarus clarkii in this wetland, as well as whether the presence of this aquatic species affects the flora. The Procambarus clarkii sampling lasted three years $(2016,2017,2018)$ in the Merja zerga wetland, using fisher-
\end{abstract}

Correspondence: Sara Saguem, Department of Biology, Faculty of Science, Abdelmalek Essaadi University, Avenue Sebta, 93002

Tetouan, Morocco.

Tel.: +212.539996432.

E-mail: sarahsaguem@gmail.com

Key words: Procambarus clarkii; macrophytes; wetland; Morocco.

Contributions: MEAEM conceived and supervised this study, SS wrote the main manuscript text and prepared figures and tables, SS and AS analysed and interpreted the data; EHJ field trip manager; MEAEM, EHJ and AS participated in discussions and provided suggestions. All the authors reviewed and approved the final manuscript.

Acknowledgements: We would like to acknowledge all the experts from Tour du Valat Research Centre for the Conservation of Mediterranean Wetlands France for their help and useful comments and documents. We are grateful to Mr Mohammed MRABET of the University of Sardinia in Italy for his advice and support. Special thanks are due to NGO's experts from Mooulay bouslham region for their unstinting field assistance.

Conflict of interest: The authors declare no conflict of interest.

Received for publication: 22 December 2019.

Accepted for publication: 18 July 2020.

${ }^{\circ}$ Copyright: the Author(s), 2020

Licensee PAGEPress, Italy

Journal of Biological Research 2020; 93:8778

doi:10.4081/jbr.2020.8778

This article is distributed under the terms of the Creative Commons Attribution Noncommercial License (by-nc 4.0) which permits any noncommercial use, distribution, and reproduction in any medium, provided the original author(s) and source are credited. men's boats. Vegetation sampling was conducted during the same Procambarus clarkii capture period to assess the abundance of Procambarus clarkii at the same time and recover the effect of this aquatic species on the flora. To strengthen our study a survey was conducted among sinners to assess the impacts of Procambarus clarkii in its living environment. The results showed that there was a significant difference in the abundance of Procambarus clarkii sampled over the years $(2016,2017,2018)$. The floristic diversity of the Merja zerga lagoon is very important. The effect of Procambarus clarkii on the flora was very remarkable. Thus, the floristic species exposed to this impact are the species of genus Potamogéton. These results show that Procambarus clarkii can be considered as a factor contributing to the decline of the floristic diversity of the aquatic areas where it lives.

\section{Introduction}

The geographical location of Morocco and the presence of two large mountain ranges, have generated a very dense hydrographic network, giving it a very important aquatic diversity, including wetlands. ${ }^{1}$

Moroccan wetlands are very rich, it is present a very important hydrological functions and a high floristic biodiversity. One of the most important wetlands on the Atlantic coast of Morocco; the Merja Zerga; this site contains remarkable flora and fauna of international importance. This area is known by the diversity of its natural habitats ${ }^{2}$ and the abundance and variability of the benthic macrofauna. ${ }^{2}$ The Merja Zerga wetland has an important socioeconomic role for the local population of more than 26,608 inhabitants due to fishing and tourism activities. ${ }^{3}$

The invasion of native communities by alien species is one of the major threats to the stability of ecosystem processes and the persistence of endemic wetland species. ${ }^{4}$ Also Merja zerga is characterized by the presence of other benthic species such as: Peringia ulvae, Scrobicularia plana, Heteromastus filiformis, Cerastoderma edule, Hediste diversicolor, Cyathura carinata and Lekanesphaera rugicauda. ${ }^{2}$

Procambarus clarkii (Girard, 1852) is an axotic species in the south-central United States (Louisiana) and in northeastern Mexico, ${ }^{5}$ recognized for its strong capacity to adapt to different environmental conditions. ${ }^{6}$ It quickly reaches the age of maturity. It has a great capacity to multiply. This species was introduced to Morocco in 2008. ${ }^{7}$

The Procambarus clarkii invading rice fields and wetlands. ${ }^{7}$ It 
is considered as a pest in several countries because of its excavation activity; it causes several damages, ${ }^{7}$ and its impact particularly on macrophyte communities. ${ }^{8}$ Especially that the macrophyte communities as primary producers are particularly sensitive to biological invasions affecting wetlands ${ }^{9}$ and rivers. In European freshwater systems, the red swamp crayfish greatly affect macrophyte cover. ${ }^{10}$

The presence of the red swamp crayfish in the Merja zerga wetland could have an impact on the floristic biodiversity. This work was carried out in this area between 2016 and 2018, with the aim of knowing the risk to the flora by monitoring the evolution of the number of macrophyte species in the presence of the Procambarus clarkii population, as well as updating the database of invasive species and making this data accessible. Many other studies have examined the impacts of crayfish invasions on macrophytes in Africa, Europe and the United States, but in Morocco this study is the first, especially on Merja zerga area.

This pioneering study in this area provide an initial understanding of the invasive nature of this alien species, as it could certainly be valuable to researchers, policy makers, conservators and managers of this wetland.

\section{Materials and Methods}

\section{Site descriptions}

Merja Zerga (long. 34॰17 N, 34॰52 N; lat. 6॰13 W; 6॰14 W) (Figure 1), is the largest lagoon on the Atlantic coast of Morocco with a surface area of 7300 ha, located in the Northwest of Morocco. $^{2}$ This area is located between the cities of Kenitra and Larache $^{2}$ and about $120 \mathrm{~km}$ north of Rabat.

The communication between this lagoon and the sea is ensured by a long and relatively narrow channel (the "throat") and is permanently maintained by the interaction of tides and continental flows. Its depth varies between 0 and $2 \mathrm{~m}$ (50 cm average depth) with the deepest points located in the drainage channels near of the gully.

Merja Zerga is always flooded with high tides. It is supplied by two permanent freshwater inlets: the Nador canal to the south and the Drader River to the north. Merja Zerga is one of the first four Moroccan wetlands to be included in the Ramsar Convention list in 1980, because of its importance for wintering migratory waterbirds. ${ }^{11}$

The hydrology of this wetland is dominated by the tidal flow that crosses the Narrows to reach the Merja Zerga wetland system; 12 it is also influenced by groundwater that emerges in several parts of the site. The lagoon system receives drainage mainly from the Drader River to the east and the Nador Canal to the south. ${ }^{12}$

The western side of the Merja Zerga is occupied by sandy soils. Within the site, intermittently flooded areas have a bottom composed of fine sand rich in organic matter, or even sandy mud or locally pure mud. ${ }^{12}$

Fishing is an important traditional activity. In the lagoon, different fishing gear and techniques are used, including gillnets (Chbek), beach seines (Chebka), sunken nets (Tarrah), trammel nets (Ters) and jumps (Kania); fish traps (Kannar) and bottom trawls (Zaouada) are also used. The fishing nets have meshes of 20 and $25 \mathrm{~mm}$, with the exception of the meshes of Zaouadaw which have meshes of 4 and $15 \mathrm{~mm} .^{12}$

The macrofauna distribution is linked to the environmental factors of the lagoon. Indeed, previous studies have shown that the spatial distribution of benthic communities in the Merja Zerga lagoon follows an upstream-downstream gradient, resulting from the combined action of all mesological factors, in particular salin- ity, edaphic parameters and hydrodynamics as well as the presence of seagrass beds. ${ }^{2}$

The salinity in Merja zerga shows a decreasing gradient from downstream to upstream of the lagoon, ${ }^{12}$ its values varied between $34 \mathrm{~g} / \mathrm{L}$ downstream $2.34 \mathrm{~g} / \mathrm{L}$ upstream. ${ }^{2}$ The salinity of the sampled sites varies between 2.34 and $8.06 \mathrm{~g} / \mathrm{L}$. the salinity had no effect on the abandonment of red swamp crayfish in our sampling sites because is very low.

\section{Sampling method}

To collect the first information on the presence of the species, and its correlation with aquatic vegetation, an anonymous survey approved by the Regional Department of Water and Forests and the Fight against Desertification North West Kenitra Morocco in collaboration with the University Abdelmalek Essaadi Faculty of Science Tetouan Morocco was used.

A well-targeted survey was distributed to fishermen in this area and two non-governmental organizations active at the local level in the field of environment, wetlands and fisheries. A total of 124 fishermen were interviewed in Merja Zerga between April 2015 and December 2018 (one field visit per month).

$100 \%$ of the fishermen questioned answered the questions in the questionnaire on the common name of red crayfish in the study area, the date and place of observation, its mode of displacement, its hypothesis of introduction, its exploitation, its impact on the fishing activity, its impact on the environment and their proposals for its control.

\section{Vegetation sampling}

Vegetation sampling was carried out over six periods in three years: the first in April and July 2016, the second in April and July 2017, and the last in April and July 2018.

The sampling plan consists of three transects A, B and C of varying lengths (Figure 1, Table 1). Difficulty in accessing the stations due to the abundance of terrestrial shrubs and grasses was the cause of this variation in length. The transect, indicated by a rope graduated in meters, starting from the area out of the water to the flooded area.

A number of five quadrats of $1 \mathrm{~m}^{2}$ were made and sampled along of each transect randomly during the two periods (once in April and once in July) each year. Within the quadrats, the species was recorded along with its abundance-dominance coefficient according to the classic Braun Blanquet scale. In each quadrat, the number of each species was recorded along with its abundancedominance coefficient relative to the total number of species collected across the transect.

Among the species harvested, only the macrophytes best represented in the study area were selected. Their recovery was estimated using a quantitative scale derived from that of abundancedominance coefficients. ${ }^{13}$

Herbariums were formed by samples of the species collected and identified at Abdelmalek Essaadi University Faculty of Science (Department of Botany) using several floristic determination keys. ${ }^{14}$

The samples collected were processed by calculation of the index of relative importance (IRp) which quantifies the abundance of each species on the transects according to this formula. ${ }^{15}$

$$
I R p=\frac{\sum \ldots(Q M p * L n m)}{L i} * 100
$$

IRp: represents the relative importance index of a species $\mathrm{p}$ on a given transect.

Lnm: represents a section of a transect.

QMp: is the average quantity index expressed as a \% of the area 
covered by a species represented in the survey to which the Braun Blanquet abundance index $+, 1,2,3,4,5$ has been assigned. $\mathrm{Li}$ : represents the total length of the transect.
The correspondence scale between the dominant abundance coefficients and the average quantities used is that proposed by Vandhen Berghen. ${ }^{16}$

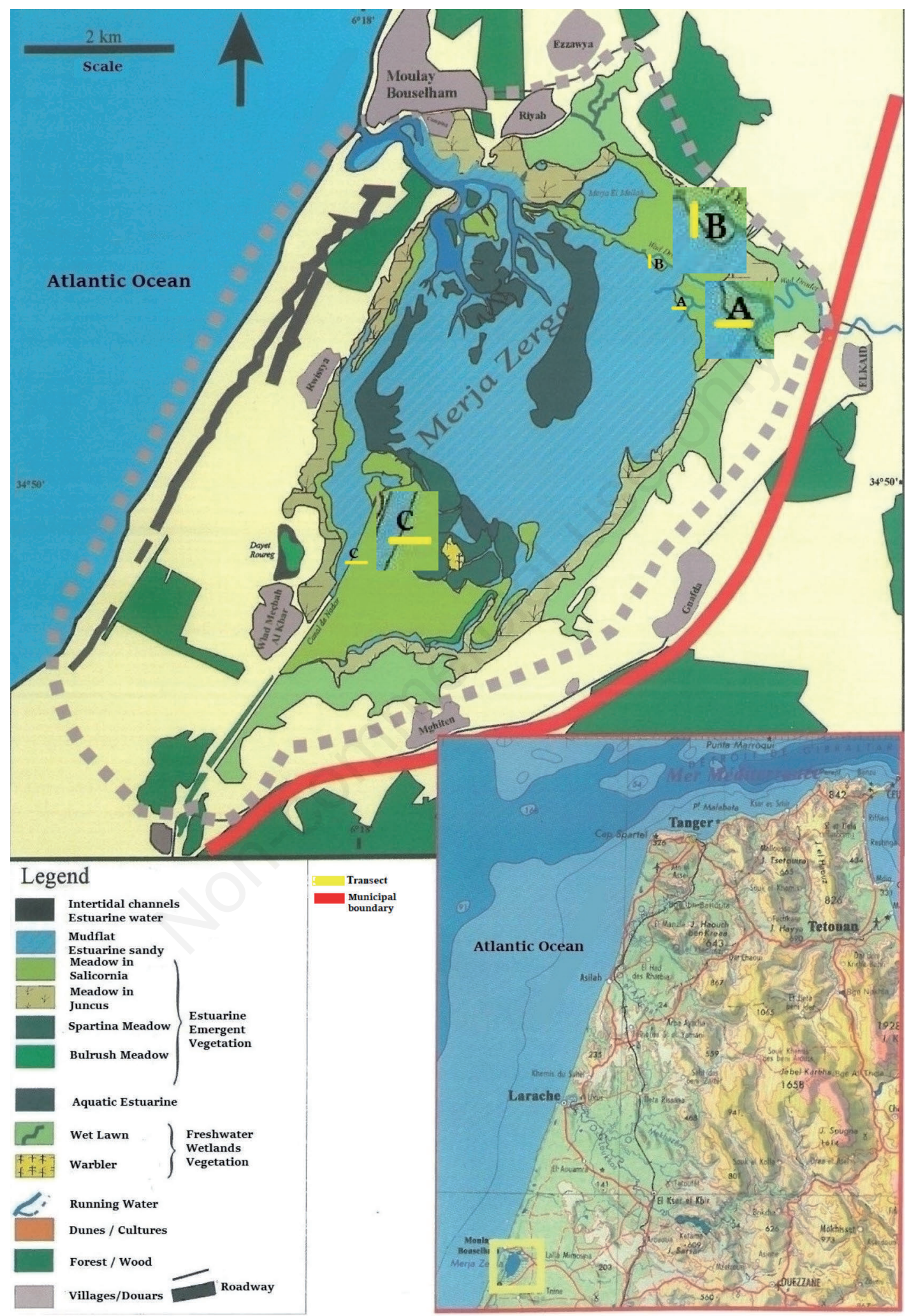

Figure 1. Location of the study area and sampling stations A, B and C. Map source: works of the scientific institute, Rabat, general ser. $\mathrm{N}^{\circ} 7,2011$, modified and translated by Saguem 2019. 


\section{The red swamp crayfish sampling}

The population of Procambarus clarkii was captured at the same time as the vegetation samples were taken, i.e. on the same day in April and July 2016, April and July 2017 and April and July 2018, during three periods of the day at 7 a.m., 2 p.m. and 7 p.m.

Crayfish sampling was carried out at several stations in the study area including station A, B and C over a total area of $100 \mathrm{~m}^{2}$ using a catch per unit effort (CPUE) of $60 \mathrm{~min}$, with a $(3 \mathrm{~mm})$ mesh net, and an altitudinal gradient of 50-100 m. The total number of Procambarus clarkii caught at all stations was then calculated as a Catch Per Unit of Effort (CPUE).

The net has been put in the water for one hour without moving it, at the same time another net of the same mesh size was tipped five times to look for crayfish.

\section{Statistical analysis}

The recorded data required a descriptive quantitative analysis. The Post-Hoc test used to test the degree of variation between years and the number of Procambarus clarkii caught. The minimum level of significance at which the null hypothesis was rejected is $\alpha=0.05$ (Table 2).

Correlation between the number of plant species sampled and the number of Procambarus clarkii caught within the same period by the Pearson correlation test (Table 3).

\section{Results and Discussion}

In the Merja Zerga where the Procambarus clarkii is present since some years ago, ${ }^{3}$ the question on the impact of this species on the habitat and native aquatic species was crucial.

Sixty-five per cent $(65 \%)$ of the respondents declared that the presence of this species in the study area has an impact on the environment. All of them add that the red swamp crayfish damage the soil by digging holes, affect water by transforming its quality, and disappear some plant and animal species. Previous studies suggest that the increasing turbidity associated with several phenomena, such as turbidity caused by red swamp crayfish, leads to a shortage of light for macrophytes. High turbidity can completely disappear macrophytes. ${ }^{17}$

The results of the survey distributed in 2015 and 2016 in this area revealed that there is an impact of the presence of this species on aquatic vegetation, which required fieldwork and inventory in 2016, 2017 and 2018 to verify, confirm this hypothesis advanced by the anglers and found the link between crayfish and aquatic vegetation abundance.

The total number of crayfish caught each in 2016, 2017 and 2018 and during three periods of the day summarized in this graph (Figure 2).

The results show that crayfish were very abundant in 2016 compared to other years (Figure 2). The number of crayfish in the study area is decreasing in 2017 and 2018, which confirms the

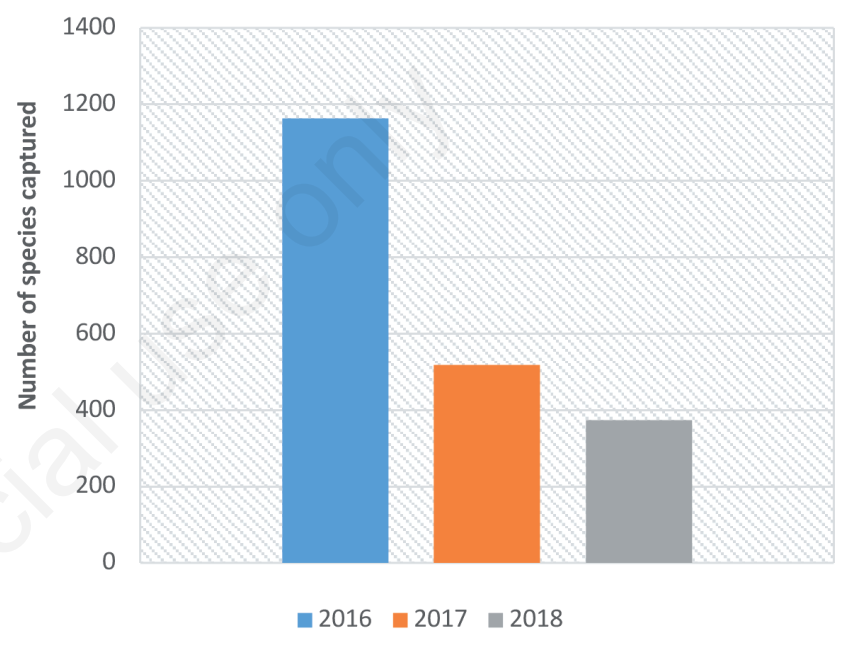

Figure 2. The Number of the Procambarus clarkii population captured in Merja zerga wetland in 2016, 2017 and 2018, Morocco.

Table 1. The location and length of transects.

\begin{tabular}{lll} 
Thransect & Length per m & Situation \\
A & 10 & The sides of the Drader River \\
B & 10 & Stagnant fresh water surface \\
\hline C & 15 & lawn influenced by the contributions of the Nador Canal \\
\hline
\end{tabular}

Table 2. Test Post-Hoc (Tukey Test) for the number of Procambarus clarkii caught during the three years (2016, 2017, 2018) (Significatif $(\mathbf{P}<0.05)$.

\section{Years}

2016 vs 2018

2016 vs 2017

2017 us 2018

*, the mean difference is significant at level 0.05 .

Table 3. Correlation matrix (Pearson) for the three years (2016, 2017, 2018).

\section{Mean difference}

\begin{tabular}{c}
$65,91^{*}$ \\
$53,83^{*}$ \\
\hline 12,083
\end{tabular}

$65,91^{*}$

12,083 
fishers' reporting in the questionnaire on the issue of the Procambarus clarkii use.

$90 \%$ of anglers replied that before 2016 , the red swamp crayfish was an alien species for them, that is why they didn't use it, but at the end of 2017, the demand for this species by anglers and fish sellers has increased due to its effectiveness as fishing bait.

Therefore, the decrease of the red swamp crayfish population is due to the high exploitation of this species.

The average difference is highly significant between the years 2016 and 2018 and moderately significant between the years 2016 and 2017, while there is no difference in averages between the years 2017 and 2018 .

According to the results of the survey with the anglers', crayfish are very abundant in the spring season. These results used as a basis for field trips and vegetation sampling.
Macrophytes are an important habitat and food source for herbivorous birds, macroinvertebrates and fish, so the decrease in their abundance influences the aquatic ecosystem. ${ }^{18}$ Grazing activity by the red swamp crayfish on macrophytes and burrowing activity can affect freshwater environments, transforming from macrophyte-dominated areas with clear waters to turbid areas dominated by phytoplankton. ${ }^{18}$

The results of flora observations in the field are summarized in a table (Table 4) using the scale mentioned in (Table 5) as well as the identification of harvested species over a three-year and quadrat method results, showed a high variation in the abundance of certain species (Table 4).

First, this table summarizes the results obtained on the abundance of plant species through colour degradation (Table 4). There are three colours in the table: the white colour indicates the group

Table 4. Covering plant collected in Merja Zerga wetland in 2016, 2017 and 2018, Morocco.

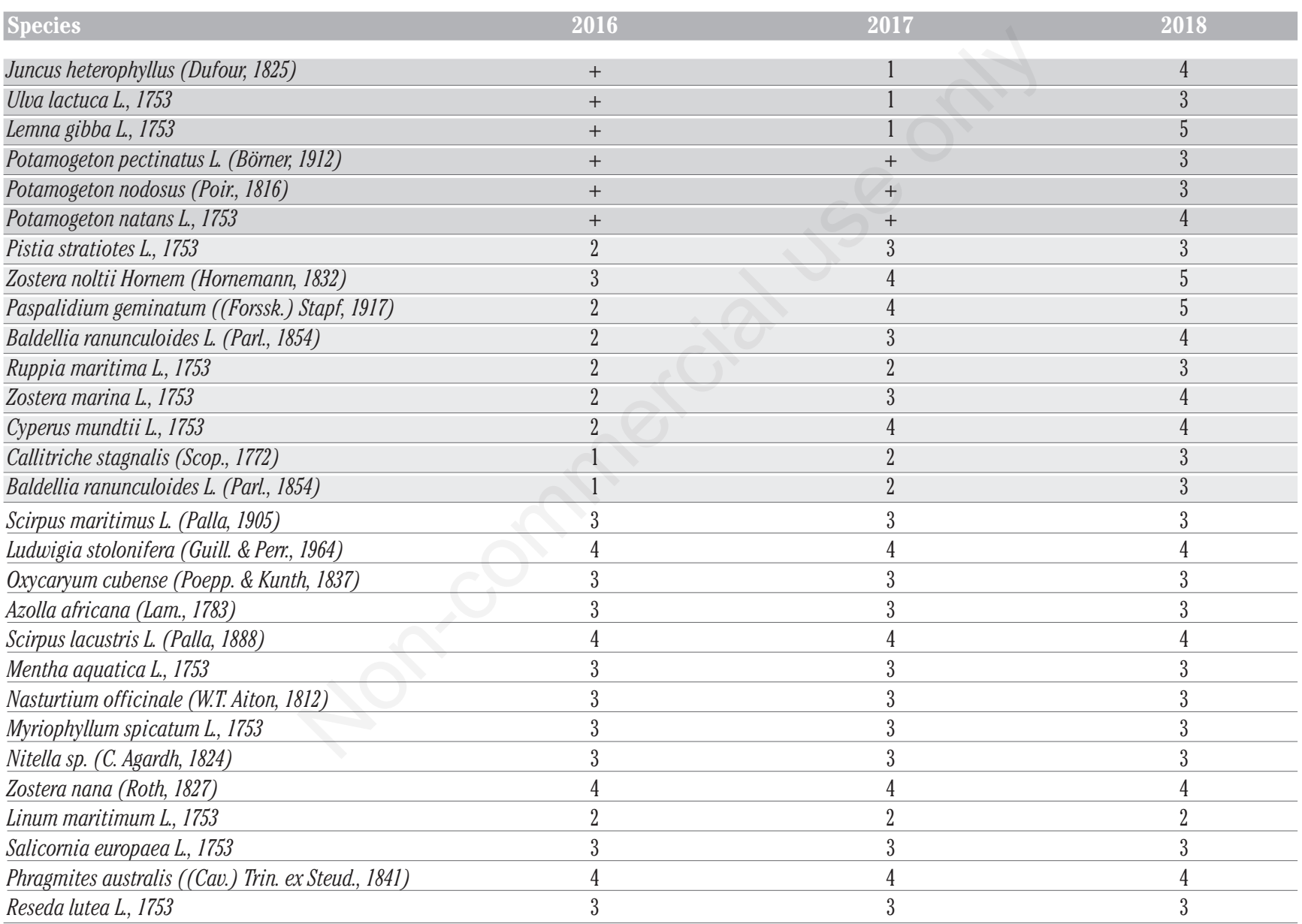

Table 5. Dominant abundance coefficients and the average quantities scale.

\begin{tabular}{lcc} 
Scale of quantity coefficients & Plant covering & Scale of the corresponding average quantities \\
5 & 75 to $100 \%$ & 0.8 \\
4 & 50 to $75 \%$ & 0.6 \\
\hline 3 & 25 to $50 \%$ & 0.3 \\
2 & 5 to $25 \%$ & 0.1 \\
\hline 1 & $<5 \%$ & 0.02 \\
\hline
\end{tabular}


of species most abundant during the three years and has no remarkable variation. The light grey colour indicates the group that underwent a slight variation in their abundance during the three years. On the other hand, the dark grey colour indicates the plant species most affected and their abundance varies from year to year.

The results of monitoring the abundance of certain plant species in the Merja zerga wetland during these three years, showed a stable abundance of some species such as Scirpus maritimus, Ludwigia stolonifera, Oxycaryum cubense, Azolla africana, Scirpus lacustris, Mentha aquatica, Nasturtium officinale, Myriophyllum sp., Nitella sp., Zostera nana, Linum maritimum, Salicornia europaea, Phragmites australis, Reseda lutea. These species appear to are not influenced by the presence of Procambarus clarkii in the area (Table 4).

In 2016, the abundance of some species was too low as Juncus heterophyllus, Ulva lactuca, Baldellia ranunculoides, Zostera noltii Hornem, Callitriche stagnalis, Cyperus mundtii, Zostera marina and Lemna gibba, but in 2017 its abundance start the increase and continued in 2018 (Table 4).

P. pectinatus, Potamogeton nodosus Poiret, Potamogeton natans are a submerged aquatic perennial macrophyte, rapidly colonizes waters and resists different pressures and conditions that are generally unsuitable for other species. ${ }^{19}$ Despite this, these species largely affected by the presence of red swamp crayfish. This impact is reflected in its low abundance in 2016 and 2017, its abundance in 2018 increased but it still remains low (Table 4).

The results of dynamics population of Procambarus clarkii and the abundance of these plant species show that there is a significant relationship. When crayfish abundance is high, vegetation abundance is low and when crayfish abundance decreases, plant species abundance increases.

This process of low abundance of these species directly linked to the presence of red swamp crayfish in this area, especially that the plant material is extremely frequent in crayfish stomachs particularly in adult. ${ }^{20,21}$

In Germany, several studies showed the strong density-dependent link between biomass and species composition of macrophytes and Procambarus clarkii. ${ }^{22}$ Also in North-Rhine Westphalia, the macrophyte community in a gravel pit lake almost entirely depleted five years after the first detection of P. clarkii. ${ }^{23}$

The variation in abundance between these species: Juncus heterophyllus, Ulva lactuca, Lemna gibba Potamogeton natans, Potamogeton nodosus and Potamogeton pectinatus (Table 4) in 2017 related to Procambarus clarkii's food preference.

A recent study examined the impact of the red swamp crayfish on the macrophyte community of Mediterranean temporary ponds, testing in laboratory if consumption and fragmentation of five macrophyte species correlated in palatability tests and in a preference test. ${ }^{24}$ The results of this study showed a high consumption of Juncus heterophyllus by Procambarus clarkii, and it avoided consuming sometimes, certain species like Carex divisa and Ranunculus peltatus. The red swamp crayfish may remove macrophyte species from the community sequentially, from the most to the least preferred species. ${ }^{25}$

Another study confirmed that the red swamp crayfish strongly inhibited the biomass of the hydrophytes Nymphoides peltata and Potamogeton spp. bygrazing, coupled with their non-consumptive plant clipping anduprooting, while, in contrast, Utricularia australis was avoided by $P$. clarkii ${ }^{24}$ the thing that is also happening at Merja Zerga wetland especially for Potamogeton species.

The excessive exploitation of the red swamp crayfish at the end of 2017 favoured the first steps of the development of vegeta- tion cover to its original state before the appearance of this species in this area.

This result by the Pearson correlation test, which showed a strong negative correlation between the abundance of plant species collected and the abundance of red swamp species caught during the same period. The red swamp crayfish may be responsible for the abundance decline of some other plant species that are not cited in this work because they are not presented and selected in our quadrats.

However, uncontrolled fishing activity in the Merja Zerga wetland, unsustainable exploitation and inadequate management of natural resources with the presence of an exotic species classified as invasive such as the red crayfish can lead to a serious deterioration of the biodiversity of this natural heritage.

\section{Conclusions}

The Merja Zerga wetland has a heritage value due to certain particularities that make it a remarkable area on a global level. Merja Zerga has a wide variety of wet habitats characterized by the presence of different plant groups and a high floristic diversity.

The disturbances it is currently experiencing on its floristic richness are related essentially to the presence of the red swamp crayfish and its uncontrolled spread in the area, these disturbances must be limited to the maximum in order to achieve sound management of this site.

\section{References}

1. Dakki M, El Hamzaoui M. Les Zones Humides du Maroc: Rapport National. AEFCS/ MedWet, 1998, 33 pp.

2. Touhami F, Bazairi H, Badaoui B, et al. Merja Zerga lagoon: study of the functional structure and bioassessment of the ecological quality of benthic communities. JMES, 2017;8;4591-9.

3. Saguem S, Sahli A, Madi A, et al. Socioeconomic impact following the introduction of the red swamp crayfish Procambarus clarkii (Girard, 1852) in Morocco. Int J Eng Sci Math 2020;9:2.

4. Simon KS, Townsend CR. Impacts of freshwater invaders at different levels of ecological organisation, with emphasis on salmonids and ecosystem consequences. Freshwater Biol 2003;48:982-94.

5. Hobbs HH. An Illustrated Checklist of the American crayfish (Decapoda: Astacidae, Cambaridae \& Parastacidae). Smithsonian Contributions to Zoology 1989;480:1-236.

6. Laurent PJ, Leloirn H, Neveu A. Remarques sur l'acclimatation en France de Procambarus clarkii (Decapoda,Cambaridae). Bull Mens Soc Linn 1991;60:166-73.

7. Saguem S, El Alami El Moutaouakil M. Study on the Spread of Procambarus clarkii at Gharb (Morocco) and Its Impact on Rice Growing. J Agricult Sci Technol A 2019;9:86-8.

8. Barr JE, Huner JV, Klarberg DP, Witzig J. The large invertebrates small vertebrate fauna of several south Louisiana crayfish ponds with emphasis on predaceous arthropods. Proc World Maric Soc 1978;9:683-700.

9. Rasmussen P, Anderson NJ. Natural and anthropogenic forcing of aquatic macrophyte development in a shallow Danish lake during the last 7000 years. J Biogeogr 2005;32:1993-2005.

10. Rodríguez CL, Bécares E, Fernández-Aláez M. Shift from clear to turbid phase in Lake Chozas (NW Spain) due to the 
introduction of American red swamp crayfish (Procambarus clarkii). Hydrobiologia 2003;506-509:421-6.

11. Wariaghli F, Tilghman-Sibille A, El Abidi A, et al. Anguilla anguilla L: Evaluation of the degree of heavy metal contamination in the Sebou estuary and in Moulay Bousselham lagoon reserve (Morocco). Int J Aquatic Sci 2013;4:69-82.

12. Thompson JR, Flower RJ, Ramdani M, et al. Hydrological characteristics of three North African coastal lagoons: insights from the MELMARINA project. Hydrobiologia 2009;622:45-84.

13. Guinoche TM. Phytosociologie. 1 vol. Paris: Masson; 1973, $227 \mathrm{p}$.

14. Maire R. Contribution à l'étude de la flore de l'Afrique du Nord, 1923-1941. Bull Soc Hist Nat Afr Nord, 14:118-59, 22:130-72, 23:163-221, 28:332-88, 32:202-24.

15. Hamel C, Bhéreur P. Méthode d'interprétation de l'évolution spatiale et temporelle des hydrophytes vasculaires. In: Studies on Aquatic Vascular Plants. Symoens JJ, Hooper SS, Compère P. (eds). Royal Botanical Society of Belgium, Brussels: 1982:294-303.

16. Vandhen Berghen $C$. Initiation à l'étude de la vegetation. 3rd edition. Jardin botanique national de Belgique, 1860 Meise, 1982, $263 \mathrm{p}$.

17. Fox AD, Jones TA, Singleton R, Agnew ADQ. Food supply and the effects of recreational disturbance on the abundance of wintering Pochard on a gravel pit complex in southern Britain. Hydrobiologia 1994;279/280:253-61.

18. Randall RG, Minns CK, Cairns VW, Moore JE. The relation- ship between an index of fish production and submerged macrophytes and other habitat features at three littoral areas in the Great Lakes. Can J Fish Aquat Sci 1996;53:35-44.

19. Samecka-Cymerman A, Kempers AJ., Toxic metals in aquatic plants surviving in surface water polluted by copper mining industry. Ecotoxicol Environ Safe 2004;59:64-9.

20. Ilheu M, Bernardo JM. Trophic ecology of red swamp crayfish Procambarus clarkii (Girard) preferences and digestibility of plant foods. Freshwat Crayfish 1995:10:132-9.

21. Gutierrez-Yurrita PJ, Sancho G., Bravo MA, Baltanas A,Montes C. Diet of the red swamp crayfish Procambarus clarkii in natural ecosystems of the DonÄana National Park temporary freshwater marsh (Spain). J Crustacean Biol 1998;18:120-7.

22. Chucholl C. Invaders for sale: trade and determinants of introduction of ornamental freshwater crayfish. Biol Inv 2013;15:125-41.

23. Gross, H., Roter amerikanischer sumpfkrebs (Procambarus clarkii) krempeltbaggersee um. Forum Flusskrebse 2013;1:36-8.

24. Gherardi F, Acquistapace P. Invasive crayfish in Europe: the impact of Procambarus clarkii on the littoral community of a Mediterranean lake. Freshw Biol 2007;52:1249-59.

25. Carreira BM, Dias MP, Rebelo R. How consumption and fragmentation of macrophytes by the invasive crayfish Procambarus clarkii shape the macrophyte communities of temporary ponds. Hydrobiologia 2014;721:89-98. 